\title{
Comparação de desempenho hidrológico de sistemas de infiltração de água de chuva: poço de infiltração e jardim de chuva
}

\author{
Comparison of hydrological performance of on-lot \\ drainage systems: dry-well and rain garden
}

\section{Ricardo Prado Abreu Reis Marina Sangoi de Oliveira Ilha}

Ricardo Prado Abreu Reis Universidade Federal de Goiás Goiânia - GO - Brasil

Marina Sangoi de Oliveira Itha Universidade Estadual de Campinas Campinas - SP - Brasil

Recebido em 14/09/13 Aceito em 10/03/14

\section{Resumo}

A

ocupação de áreas urbanas produz impactos significativos no equilíbrio do balanço hídrico das cidades. Como consequência da impermeabilização de áreas edificadas tem-se o aumento do escoamento superficial, que ocasiona maior frequência de cheias urbanas. Visando diminuir o impacto ocasionado pela ocupação, soluções técnicas compensatórias, fundamentadas em técnicas de infiltração de água pluvial, vêm sendo amplamente propostas para os projetos de sistemas prediais. Este trabalho objetiva comparar o desempenho hidrológico de dois sistemas de infiltração no lote: um jardim de chuva e um poço de infiltração. Para tanto, foram monitoradas as vazões de entrada, o volume infiltrado e o volume extravasado durante eventos de chuva simulados. Os sistemas de infiltração de água foram implantados em uma área experimental, e o monitoramento dos parâmetros foi feito por meio de sensores de nível de água e medidores de vazão de alta precisão. Assim, foi possível construir os hidrogramas de saída dos sistemas e mensurar a parcela de infiltração de água durante a operação deles. Como resultado avaliou-se a relevância de se considerar a parcela de infiltração no dimensionamento dos sistemas de infiltração de água de chuva. Além disso, observaram-se um melhor desempenho de amortecimento de pico de vazão do hidrograma no jardim de chuva e maior eficiência de redução de volume escoado por parte do poço de infiltração.

Palavras-chave: Drenagem na fonte. Poço de infiltração. Jardim de chuva.

\footnotetext{
Abstract

The occupation of urban areas impacts urban water balance. Waterproofing of the urban soil causes run-off to increase, generating more frequent flooding in cities. In order to reduce the impact caused by occupation, compensatory strategies based on soil infiltration techniques are now often proposed in the design of building systems. This paper compares two on-lot infiltration systems: a rain garden and a dry-well. Infiltration systems were installed in an experimental area and the investigation involved monitoring these parameters using level sensors and high precision water meters. Water inflow, infiltrated volume and overflow were analysed in simulated rain events. The results indicate the importance of considering the infiltration portion in the dimensioning of the infiltration systems. Furthermore, a better performance of the rain garden was observed in decreasing the peak flow rate, and higher efficiency of the run-off volume when considering the drywell.

Keywords: On-lot drainage. Drywell. Rain garden.
} 


\section{Introdução}

Os impactos ocasionados pelo processo de urbanização têm-se mostrado mais intensos nas últimas décadas. Estima-se que em 2030 a população concentrada em centros urbanos atinja a marca de $60 \%$ do total (WORLD..., 2009). No Brasil, na região hidrográfica do Paraná, por exemplo, onde se localiza a cidade de São Paulo, a população urbana já atingiu mais de $90 \%$ (AGÊNCIA..., 2007; IBGE, 2010).

A grande concentração populacional em áreas urbanas implica mudanças significativas nas características do ambiente ocupado. O processo de urbanização acelerado na maioria dos casos ocorre de forma não planejada e, quase sempre, vem acompanhado de uma série de impactos ambientais e problemas de infraestrutura urbana.

O desequilíbrio do balanço hídrico pode ser citado como um dos grandes impactos gerados nas regiões ocupadas. A diminuição do volume de água infiltrada no solo em uma área urbanizada é significante se comparada às condições originais das regiões com grande urbanização. A alteração no hidrograma de escoamento superficial é constituída por acréscimo nos picos de vazões, com o aumento do volume em um curto espaço de tempo. Como resultado, têm-se as enxurradas e cheias urbanas (CARVALHO, 2008).

A solução convencional para a drenagem urbana consiste na execução de galerias pluviais para a coleta e transporte do excesso de escoamento superficial para pontos à jusante das áreas urbanas. Entretanto, essa forma de concepção de sistemas de drenagem nem sempre suporta a magnitude das vazões de escoamento nos pontos de descarga. $\mathrm{O}$ problema se agrava devido aos seguintes fatores: impermeabilização de grandes áreas urbanas ocasionada pela ocupação desordenada, pontos de redes de drenagem subdimensionados e mau funcionamento dessas galerias em função de entupimentos provocados pelo lixo não coletado ou disposto incorretamente.

Com a tendência de adoção de conceitos de desenvolvimento de baixo impacto ambiental, soluções complementares de drenagem urbana vêm sendo estudadas ao longo das últimas décadas. Esse conceito se traduz na tentativa de manutenção das condições de equilíbrio do balanço hídrico existentes no período de prédesenvolvimento. As soluções devem ser implementadas diretamente na fonte de geração do problema. Para tanto, deve-se utilizar novos conceitos como os dispositivos de acréscimo de infiltração, de armazenamento e retardo do escoamento, além de integração de medidas não estruturais, que visem à prevenção das causas dos problemas, e não de seus efeitos (REIS et al., 2006).

Entre as técnicas compensatórias de drenagem urbana para a solução desse problema, podem ser citados os sistemas de drenagem na fonte, os quais se constituem em ferramentas que possibilitem o manejo mais sustentável das águas pluviais e, assim, integrem soluções de drenagem que gerem menor impacto durante o uso e ocupação do solo em áreas urbanas. Vários são os tipos de sistemas que vêm sendo estudados para esse fim, e a seleção da solução mais adequada passa pela análise de diferentes fatores, tais como características do solo (capacidade de infiltração e capacidade estrutural), nível do lençol freático e área disponível para a implantação no lote, entre outros (REIS; OLIVEIRA; SALES, 2008).

Alguns estudos indicam que os sistemas de infiltração no lote podem reduzir em até $100 \%$ o volume de escoamento superficial considerado no projeto (SOUZA; GOLDENFUM; BARRAUD, 2002; LIMA, 2009), desde que haja espaço e solo com características estruturais e de permeabilidade adequados aos sistemas de infiltração.

Entre as inúmeras variações de concepção dos sistemas de drenagem no lote, os sistemas de infiltração de água de chuva são os mais adotados, por serem consideradas as soluções que proporcionam maior sustentabilidade entre as técnicas de drenagem de água pluvial. Apesar disso, é necessário ressaltar que esse modelo é relativamente novo, e estudos que consideram sua integração com os sistemas prediais de águas pluviais também são escassos, pois a maioria das pesquisas trata os sistemas de drenagem na fonte como unidades independentes e aplicam técnicas de estudos adequadas para grandes áreas.

Assim, este estudo visa comparar o desempenho do poço de infiltração, um sistema que já é bastante utilizado em algumas regiões do país, com outro sistema ainda pouco explorado nacionalmente, como solução de drenagem de água pluvial aplicável a sistemas prediais, que é o jardim de chuva. A comparação entre esses sistemas visa demonstrar que existem soluções distintas de infiltração de água de chuva que podem ser aplicadas a sistemas prediais, cada uma com suas vantagens, de acordo com cada situação.

O poço de infiltração consiste em uma escavação no solo revestida por tubos de concreto perfurados ou tijolo assentado em crivo; sua lateral e fundo são preenchidos com brita envolta em geotêxtil. Durante as chuvas prolongadas, em que a região de 
contorno do poço fica saturada, o poço enche e passa a funcionar como reservatório de retenção. Caso o poço atinja sua capacidade máxima de operação, a água excedente é conduzida por meio de um extravasor para o sistema convencional de captação de água pluvial. Pode reter e infiltrar $100 \%$ de determinada chuva de projeto, desde que haja disponibilidade de área e de condições adequadas de parâmetros locais, tais como nível do lençol freático, capacidade de infiltração do solo e capacidade estrutural do solo.

Além disso, estudo desenvolvido para a avaliação do desempenho desse sistema no controle de cheias urbanas, considerando poços de $500 \mathrm{~L}$ de volume interno, apontou para reduções de $10 \%$ a $20 \%$ na vazão de pico para chuvas com diferentes períodos de retorno. Para chuvas com período de retorno inferior a 1 ano, foram observadas reduções de até $80 \%$ (SCHILLING, 1982). Quando comparado com um poço escavado em solo sem revestimento, o poço de infiltração apresenta um coeficiente de infiltração cerca de 19 vezes maior (REIS; OLIVEIRA; SALES, 2008).

Roldin et al. (2012) destacam que, se fossem implantados poços de infiltração interligados a $8 \%$ das áreas impermeáveis em uma área urbanizada de $3,0 \mathrm{~km}^{2}$, seria possível reduzir $24 \%$ do escoamento superficial anual na cidade estudada.

Xiao et al. (2007) demonstraram que, dentre os sistemas avaliados para escala residencial, aquele composto de guias e poço de infiltração proporcionam redução de $65 \%$ no volume de escoamento superficial para uma chuva de projeto de 50 anos no local investigado.

Os jardins de chuva, por sua vez, constituem-se em uma das soluções mais simples para o controle de escoamento na fonte. São, em geral, compostos de áreas permeáveis rebaixadas em relação ao nível natural do terreno, com plantas e/ou preenchidas com material granular, as quais recebem a descarga do volume de água de chuva precipitada sobre uma área impermeável. Essas áreas podem receber drenos transversais, para facilitar a infiltração do volume de água precipitado. Esse sistema pode reduzir em até $88 \%$ o volume médio anual de escoamento superficial (JACOBSON, 2007).

James e Dymond (2012) verificaram que o uso de jardins de chuva poderia reduzir $37 \%$ do volume escoado durante as chuvas de até 10 anos de período de retorno no local de estudo.

Davis et al. (2012) concluíram ser muito difícil estabelecer um padrão único para a concepção de jardins de chuva, pois são muitas as variáveis que podem influenciar no desempenho hidrológico dele.

\section{Material e métodos}

Foram executados dois sistemas de infiltração em uma área experimental para o desenvolvimento deste estudo, um jardim de chuva e um poço de infiltração. Esses sistemas foram dimensionados de forma a receber em seu interior a vazão de chuva captada por uma cobertura de fibrocimento de $10 \mathrm{~m}$ x $5 \mathrm{~m}$ com inclinação de $10 \%$. O experimento conta com bombas centrífugas com vazão regulável e medidores classe " $D$ " para a medição da vazão de água em tempo real.

O pré-dimensionamento dos sistemas de infiltração foi feito considerando a equação racional (Equação 1) para a determinação da vazão produzida por uma chuva de projeto com período de retorno de 5 anos, com duração de $10 \mathrm{~min}$, precipitada sobre a cobertura existente no aparato experimental. A chuva de projeto foi definida de acordo com a Equação 2, proposta por Zuffo e Leme (2005). Segundo os referidos autores, essa equação é adequada para a determinação de chuvas para a cidade de Campinas, com período de retorno entre 2,33 e 100 anos, e tempo de duração entre $10 \mathrm{~min}$ e $120 \mathrm{~min}$.

$\mathrm{Q}=\frac{\mathrm{C} . \mathrm{i} . \mathrm{A}}{60}$

Eq. 1

Em que:

Q: vazão de projeto em (L/min);

i: intensidade de chuva $(\mathrm{mm} / \mathrm{h})$; e

A: área de contribuição $\left(\mathrm{m}^{2}\right)$.

$\mathrm{i}=\frac{2.357,83 \mathrm{~T}_{\mathrm{r}}^{0.188}}{(\mathrm{t}+20)^{(0,917)}}$

Eq. 2

Em que:

i: intensidade de chuva $(\mathrm{mm} / \mathrm{h})$;

Tr: período de retorno (anos); e

t: duração da chuva (min).

Após a execução dos sistemas, os cálculos para a determinação da capacidade deles foram refeitos, a fim de considerar as características do material de preenchimento, tais como granulometria e porosidade, e também aspectos pós-execução, como o posicionamento dos tubos extravasores. Assim, padronizou-se uma métrica para a avaliação da capacidade dos sistemas de infiltração, estabelecendo um valor percentual em relação ao volume de uma chuva com período de retorno de 5 anos e duração de 10 min, precipitada sobre a área de contribuição. 
A taxa de infiltração foi desconsiderada nesse dimensionamento dos sistemas, seguindo as recomendações de Campisano, Creaco e Modica (2011), que consideram muito baixo o percentual infiltrado em terrenos argilosos de baixa permeabilidade, para ser considerado na determinação do volume de sistemas de infiltração de água de chuva dimensionados com chuvas intensas e de pequena duração.

Dessa forma, o jardim de chuva poderia reter e infiltrar $898 \mathrm{~L}$, ou seja, aproximadamente $72 \%$ do volume gerado pela chuva de projeto. Já o poço de infiltração teria uma eficiência de $75 \%$, correspondente à retenção e infiltração de $934 \mathrm{~L}$, para esse mesmo volume de chuva.

Por fim, considerou-se no dimensionamento que os sistemas deveriam esgotar toda a água retida em um período máximo de $6 \mathrm{~h}$, a fim de possibilitar um bom funcionamento durante eventos consecutivos de chuvas de grande intensidade. Para tanto, a taxa de infiltração do solo foi determinada por meio dos valores médios de um ensaio de rebaixamento de água feito no local de estudo em três poços de $0,15 \mathrm{~m}$ de diâmetro e 2,50 $\mathrm{m}$ de profundidade, escavados a trado sem revestimento, conforme critérios da ABGE (ASSOCIAÇÃO..., 1996), resultando igual a uma taxa de infiltração de 2,53 x $10-5 \quad \mathrm{~m} 3 / \mathrm{m} 2 / \mathrm{s}$. Amostras retiradas a cada $0,50 \mathrm{~m}$ de escavação desses três poços, até a profundidade de $2,50 \mathrm{~m}$, indicaram que o solo pode ser classificado entre argila arenosa e silte arenoso, conforme o método de classificação granulométrica (CASAGRANDE, 1948).

A cada simulação, uma parcela da água reservada em um reservatório de $20 \mathrm{~m} 3$ foi bombeada e direcionada por meio de condutores de $100 \mathrm{~mm} \mathrm{e}$ $50 \mathrm{~mm}$, para o enchimento do jardim de chuva e do poço de infiltração. Esses condutores foram montados de forma a representar condições encontradas normalmente em sistemas prediais de água pluvial, sendo possível a realização de ajustes para avaliação de situações distintas de escoamento, existência de refluxo, condições de extravasamento, entre outras.

Para a avaliação do desempenho hidrológico dos sistemas de infiltração, além dos medidores de vazão, também foram empregados sensores de nível de água posicionados dentro de cada unidade de infiltração (jardim e poço), e, também, dentro de reservatórios interligados a jusante do extravasor de cada sistema. Assim, foi possível traçar os hidrogramas levando-se em consideração as vazões de entrada e saída e os intervalos de tempo necessários para o enchimento total e o esgotamento deles.
Antes de cada ensaio, os sistemas de infiltração foram enchidos e esvaziados por três vezes consecutivas, a fim de elevar o grau de umidade e de saturação do solo na região de contorno, de modo a simular a pior condição de funcionamento deles. Esse procedimento foi adotado porque se consegue atingir a capacidade de campo apenas alguns minutos após o total enchimento do sistema de infiltração. Entretanto, os quatro enchimentos e esvaziamentos consecutivos em intervalos de 6h:12h:6h, considerando vazões de chuva de elevada intensidade, geram uma condição que dificilmente ocorrerá em um cenário real. Com isso, cria-se uma condição pior de funcionamento do que apenas um ou dois enchimentos. Assim, só foram considerados como resultados para as análises os dados coletados a partir do $4^{\circ}$ procedimento de enchimento.

\section{Características construtivas do jardim de chuva}

O jardim de chuva (Figura 1) foi construído no formato trapezoidal, com as seguintes dimensões: base menor com $1,40 \mathrm{~m}$ x $0,90 \mathrm{~m}$; base maior com 2,0 m x 1,5 m; e profundidade útil de 0,465 m. Foi plantada Zoysia japonica - grama-esmeralda - em placas nas paredes laterais. No fundo foi criada uma área com pedras de seixo, abaixo da posição de descarga da água; no restante da superfície do fundo foi espalhada casca de pinos, a fim de manter a umidade do solo. A umidade elevada é importante para a manutenção das plantas e para evitar o endurecimento e a impermeabilização da camada superficial do solo devido à exposição direta ao sol e à chuva.

No centro do jardim de chuva foi instalado um dreno vertical de $100 \mathrm{~mm}$ de diâmetro e $1,0 \mathrm{~m} \mathrm{de}$ profundidade, composto de agregados do tipo brita $\mathrm{n}^{\mathrm{o}} 1$, revestido com manta geotêxtil, fazendo a interface entre a brita e o solo. Por fim, foram plantadas duas mudas de Duranta erecta aurea, conhecida popularmente por pingo-de-ouro, para auxiliar no processo de infiltração de água de chuva no solo. Essa espécie foi escolhida devido a sua resistência ao sol e a inundações do sistema, porque as mudas ficavam total ou parcialmente submersas por intervalos de aproximadamente $6 \mathrm{~h}$.

\section{Características construtivas do poço de infiltração}

O poço de infiltração consiste de uma escavação cilíndrica de $1,10 \mathrm{~m}$ de diâmetro e $1,50 \mathrm{~m}$ de profundidade (Figura 2). 
Figura 1 - Jardim de chuva utilizado para a avaliação de desempenho hidrológico
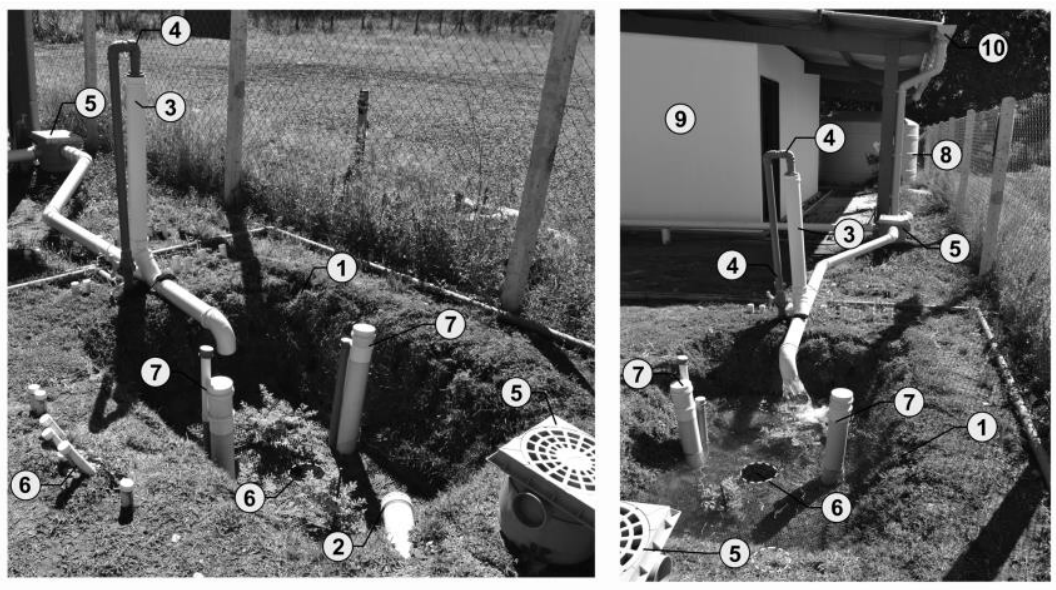

Legenda:

(1) Jardim de chuva $\mathrm{N}^{0} 1$ (base maior $2,0 \times 1,5 \mathrm{~m}$ e base menor $1,4 \times 0,9 \mathrm{~m}$ e altura útil $=0,47 \mathrm{~m}$ )

(2) Extravasor com crivo (fluxo segue até o reservatório de captação de água extravasada)

(3) Condutor de água para descarga de chuva simulada no jardim de chuva (PVC esgoto DN100)

(4) Condutor de água bombeada para descarga de chuva simulada no jardim de chuva (PVC soldável DN50)

(5) Caixa de água pluvial com grelha para avaliar ocorrências de possiveis refluxos

(6) Posição do dreno de brita $n^{\circ} 1$ (diâmetro $100 \mathrm{~mm}$ envolto em manta geotêxtil e profundidade de $1,0 \mathrm{~m}$ )

(7) Tubos para a inserção dos sensores de nivel de água

(8) Reservatórios de $10 \mathrm{~m}^{3}$ (2 unidades)

(9) Abrigo do sistema de bombeamento e datalogger da estação meteorológica

(10) Calha PVC seção semicircular e declividade de $0,5 \%$ para a captação de água de chuva

Figura 2 - Fases de execução do poço de infiltração de água de chuva utilizado para a avaliação de desempenho hidrológico
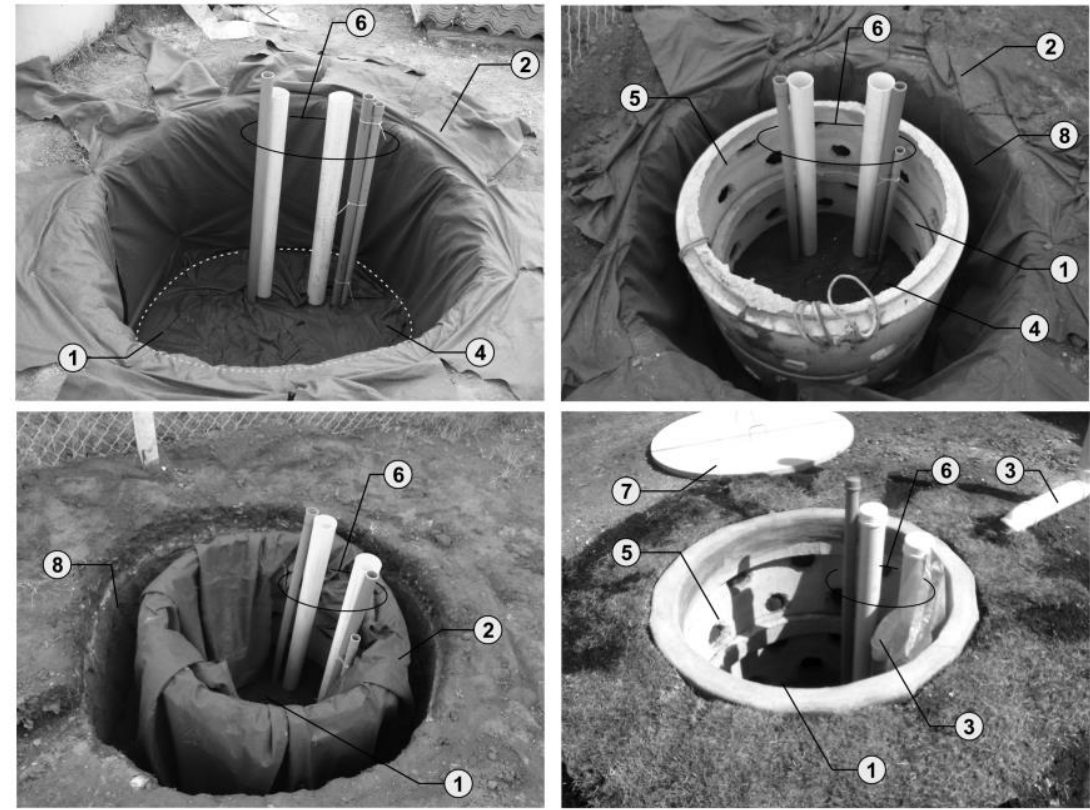

Legenda:

(1) Poço de infiltração $(\mathrm{DI}=110 \mathrm{~mm}$, profundidade $=1,50 \mathrm{~m}$, sendo $0,50 \mathrm{~m}$ da camada de brita mais $1,0 \mathrm{~m}$ de altura livre até a tampa)

(2) Manta geotêxtil envolvendo a camada de brita do fundo e fazendo a interface entre parede lateral do poço e o solo

(3) Condutor de água para descarga no poço de infiltração

(4) Fundo - camada de brita $\mathrm{n}^{\circ} 1 \mathrm{com} 0,50 \mathrm{~m}$ envolta em manta geotêxtil

(5) Tubo de concreto com $1,10 \mathrm{~m}$ de diâmetro interno e com 20 perfurações de $100 \mathrm{~mm}$ de diâmetro cada

6. Tubos para a inserção de sensores de nivel de água e outros equipamentos utilizados em ensaios futuros

(7) Tampa de concreto

(8) Área lateral de escavação ao final preenchida com brita $n^{\circ} 1$ (distância média de $10 \mathrm{~cm}$ da parede lateral do poço) 
A parede lateral foi executada com dois tubos de concreto sobrepostos (tubo do tipo "zimbra" utilizado para a execução de cisternas). Os tubos foram perfurados manualmente, totalizando 20 furos com diâmetro de aproximadamente $100 \mathrm{~mm}$ cada, o que equivale a $9,1 \%$ de área vazada em relação à área de superfície do tubo. Os tubos foram revestidos externamente com manta geotêxtil, e a lateral, preenchida com agregados do tipo brita $\mathrm{n}^{\circ} 1$, fazendo a interface entre manta $\mathrm{e}$ solo.

O fundo é composto de uma camada de $50 \mathrm{~cm}$ de material granular limpo (brita $\mathrm{n}^{\circ} 1$ ), revestido por manta geotêxtil. Esse material de preenchimento apresenta porosidade que varia entre $22,54 \%$ (estado fofo) e 19,43\% (estado compactado), definida em laboratório.

A Figura 3 apresenta o perfil granulométrico do material de preenchimento utilizado no fundo e na lateral do poço de infiltração. Por fim, a altura útil acima da camada de brita totalizou $0,87 \mathrm{~m}$, devido à instalação do tubo extravasor.

\section{Avaliação do desempenho hidrológico}

Visando avaliar os sistemas de infiltração de água de chuva sob condições de funcionamento próximas e acima da vazão de projeto, foram adotadas duas chuvas de ensaio com duração de 10 min, a primeira chuva, com valor inferior à chuva de projeto, e período de retorno de 3 anos (vazão igual a $6,8 \mathrm{~m}^{3} / \mathrm{h}$ ), e a segunda chuva com valor superior à chuva de projeto, com período de retorno de 10 anos (vazão igual a $8,5 \mathrm{~m}^{3} / \mathrm{h}$ ).

Para a avaliação do desempenho dos sistemas de infiltração foram monitorados o tempo de enchimento do jardim de chuva e do poço de infiltração e os volumes retido, infiltrado e de extravasamento. Os hidrogramas construídos para as vazões de saída e entrada nos sistemas de infiltração foram comparados com o hidrograma representativo do sistema sem nenhuma estratégia de infiltração, gerado por meio do método FHA (FEDERAL..., 2001), utilizado para o cálculo do tempo de concentração em pequenas áreas construídas e, também, observando o escoamento em tempo real na estrutura de ensaio (cobertura, calha, condutores de água pluvial).

Por fim, também foi avaliada a porcentagem do volume que infiltra durante dois períodos de enchimento dos sistemas investigados, a fim de verificar se essa parcela é realmente relevante para o dimensionamento do sistema de infiltração. Para tanto, foram considerados o intervalo imediatamente anterior ao extravasamento e o período imediatamente após o término do extravasamento.

\section{Resultados e discussão}

A Figura 4a apresenta os hidrogramas de saída do sistema predial de água pluvial com e sem os sistemas de infiltração em estudo para a vazão de $6,8 \mathrm{~m}^{3} / \mathrm{h}$ (período de retorno de 3 anos) e duração de $10 \mathrm{~min}$.

O poço de infiltração foi capaz de suportar toda a vazão gerada pela chuva de projeto, sem extravasar (Figura 4a). Assim, 100\% da água de chuva foi infiltrada no próprio terreno, indicando preliminarmente um dimensionamento adequado do sistema, já que ele havia sido dimensionado para uma chuva superior a do ensaio realizado. Já o jardim de chuva, em média, extravasou após 7 min e $10 \mathrm{~s}$ do início do escoamento e reteve aproximadamente $60 \%$ da água gerada pela chuva de projeto até esse período. Esse valor é em média $13,5 \%$ abaixo do esperado para essa vazão de ensaio. Para ajustar a capacidade de projeto do sistema de infiltração ao volume de ensaio, seria necessário elevar $2,0 \mathrm{~cm}$ no nível do tubo extravasor.

A fim de avaliar as condições de extravasamento dos dois sistemas de infiltração, a vazão de 6,8 $\mathrm{m}^{3} / \mathrm{h}$ foi prolongada por mais $8 \mathrm{~min}$, totalizando uma chuva com duração de 18 min (Figura 4b). Para esta duração de chuva, em média, o poço de infiltração extravasou aos 14 min e $50 \mathrm{~s}$ após o início do escoamento, e, após extravasar, houve amortecimento no pico da vazão máxima do hidrograma de aproximadamente $16 \%$. Já o jardim de chuva gerou amortecimento médio no pico de vazão de aproximadamente $22 \%$.

Figura 3 - Perfil granulométrico do material de preenchimento (brita $n^{\circ} 1$ ) utilizado na composição do fundo e das laterais do poço de infiltração

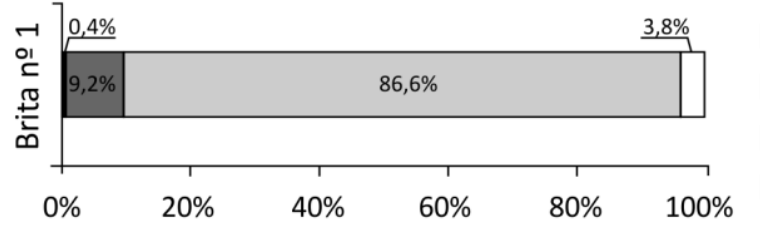

Pedregulho fino (2,0 a 4,80 $\mathrm{mm})$

Pedregulho fino/médio (4,81 a 9,50 mm)

$\square$ Pedregulho médio (9,51 a 19,0 mm)

$\square$ Pedregulho médio $(19,01$ a $25,0 \mathrm{~mm})$

84 Reis, R. P. A.; Ilha, M. S. de O. 
Apesar do maior volume extravasado, o jardim de chuva proporcionou amortecimento do pico de vazão no hidrograma um pouco mais elevado que o poço de infiltração. Após ensaios comparativos realizados no jardim de infiltração, esse fenômeno foi atribuído principalmente ao crivo instalado no extravasor do sistema, responsável por proteger contra a entrada de sujeira (gravetos, folhas e outros) o condutor horizontal de água pluvial. Supõe-se que o amortecimento do pico de vazão também é influenciado, em menor proporção, pelas plantas, que, por sua estrutura física e de enraizamento, facilitam a entrada da água no solo e aumentam a capacidade de retenção de água no sistema.

A Figura 5a apresenta a média das porcentagens de água retida, infiltrada e extravasada em dois períodos de análise para o poço de infiltração, e a Figura $5 \mathrm{~b}$ apresenta esses resultados para o jardim de chuva, ambos para a vazão de $6,8 \mathrm{~m}^{3} / \mathrm{h}$. No período T1, têm-se os volumes percentuais imediatamente anteriores à ocorrência de extravasamento, e no período $\mathrm{T} 2$, os volumes percentuais imediatamente após o final do escoamento no extravasor.

No período T1, aproximadamente um terço do volume de água descarregado dentro do poço foi infiltrado nos $15 \mathrm{~min}$ iniciais. No período T2, igual a 21 min e $30 \mathrm{~s}$, contabilizados após o início da chuva simulada, $84,3 \%$ do volume gerado até aquele momento foi retido e infiltrado pelo sistema.

Por sua vez, somente $5,5 \%$ da água descarregada dentro do jardim no período $\mathrm{T} 1$ havia sido infiltrada até o início do extravasamento, que ocorreu 7 min e 30 s após o início da chuva simulada. Já no intervalo T2, imediatamente após o final do escoamento no extravasor, aos $22 \mathrm{~min}$ e $50 \mathrm{~s}$ após o início da chuva simulada, $49,8 \%$ do volume gerado foi retido e infiltrado pelo sistema.

\section{Figura 4 - Hidrogramas de saída do sistema predial de água pluvial considerando cenários com e sem sistema de infiltração}
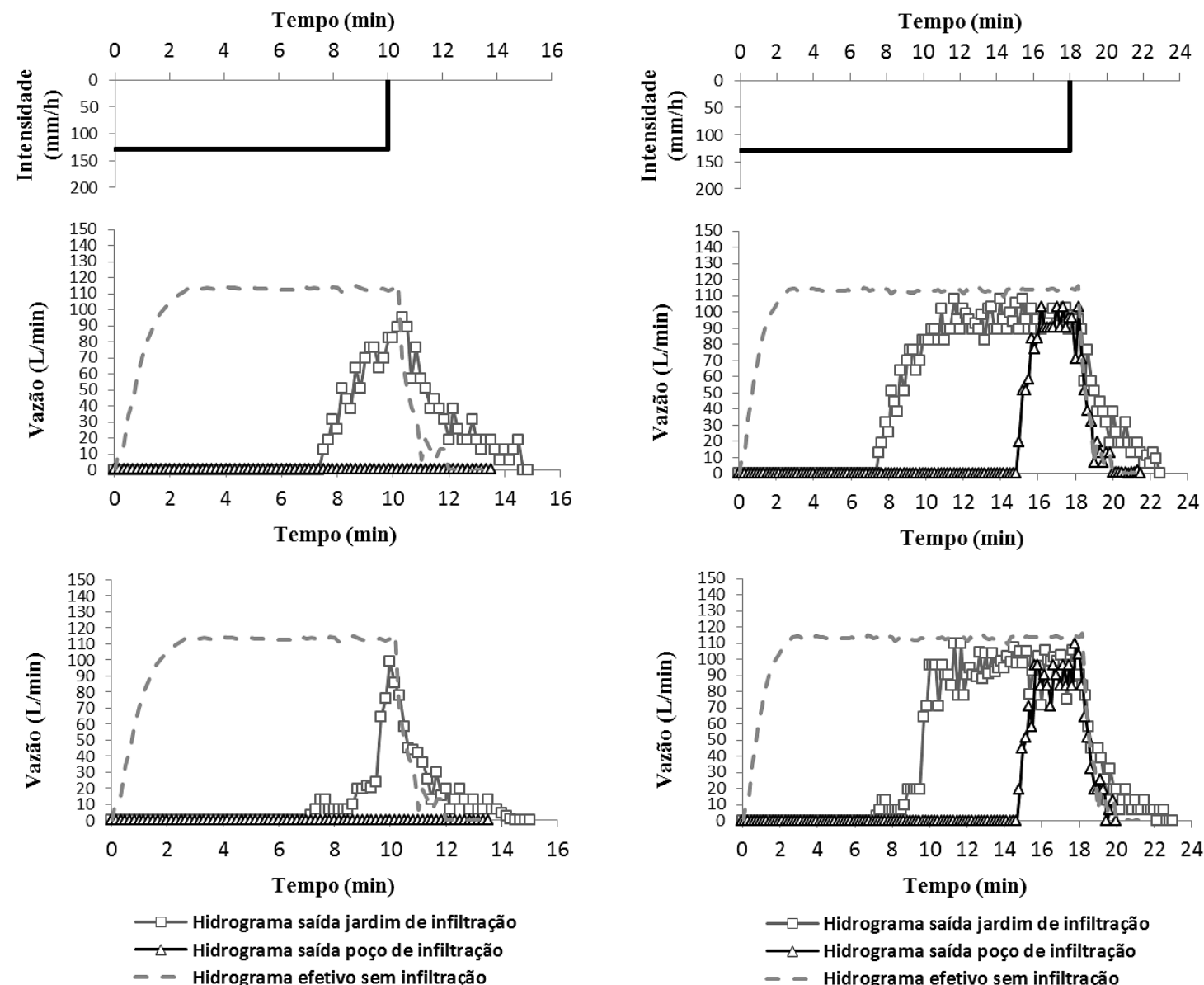

(a)

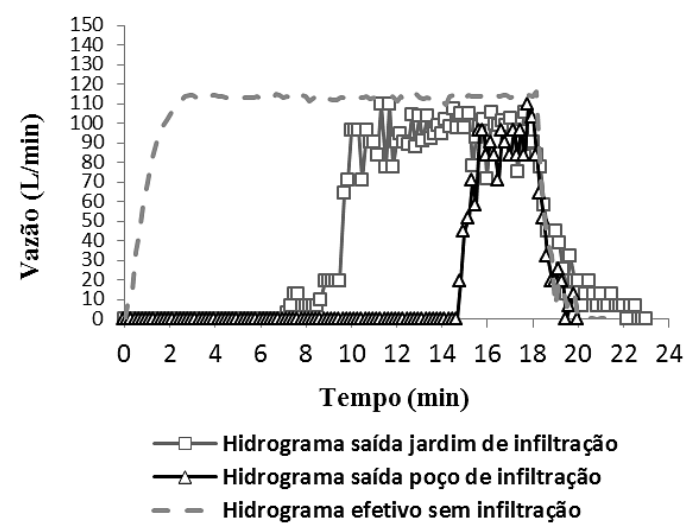

(b)

Nota: (a) Chuvas com período de retorno de 3 anos, vazão de $6,8 \mathrm{~m}^{3} / \mathrm{h}$ e duração de $10 \mathrm{~min}$ e (b) Prolongamento da vazão de $6,8 \mathrm{~m}^{3} / \mathrm{h}$ por um período de $18 \mathrm{~min}$, a fim de avaliar as condições de extravasamento. 
No caso do poço de infiltração, pode-se dizer que a parcela do volume infiltrado inicialmente é um valor relevante para o dimensionamento do sistema de infiltração, mesmo para um solo de baixa taxa de permeabilidade e uma chuva de projeto de curta duração, parâmetros presentes no ensaio em questão. Já para o jardim de chuva, a parcela de infiltração representaria menor impacto no dimensionamento, já que o volume infiltrado durante o enchimento do sistema foi bem inferior.

A Figura 6a apresenta os hidrogramas de saída do sistema predial de água pluvial com e sem os sistemas de infiltração em estudo para a vazão de $8,5 \mathrm{~m}^{3} / \mathrm{h}$, correspondente à chuva com período de retorno de 10 anos e duração de $10 \mathrm{~min}$.

O poço de infiltração em todos os ensaios realizados para essa configuração comportou $100 \%$ da vazão descarregada no sistema sem extravasar, ou seja, $100 \%$ da água de chuva foi infiltrada no próprio lote. Assim, pode-se dizer que há, nesse caso, um superdimensionamento do sistema de infiltração, já que ele havia sido dimensionado para uma chuva com vazão de 7,48 $\mathrm{m}^{3} / \mathrm{h}$, que é inferior à empregada nos ensaios.

Por outro lado, em média, o jardim de chuva extravasou após 6 min e reteve $60 \%$ da água descarregada no sistema até aquele período. Esse valor é, em média, 14\% inferior à capacidade de retenção esperada em projeto, o que demonstra que este sistema encontra-se subdimensionado, sendo necessário aumentar o volume de retenção para atingir o desempenho de projeto.

A fim de avaliar as condições de extravasamento dos sistemas de infiltração, a vazão de $8,5 \mathrm{~m}^{3} / \mathrm{h}$ foi prolongada por mais $7 \mathrm{~min}$, totalizando uma chuva com duração de 17 min. Para esta configuração, em média, o poço de infiltração extravasou aos 11 min e $40 \mathrm{~s}$ decorridos após o início do funcionamento e, após extravasar, houve amortecimento médio no pico da vazão máxima do hidrograma de $13,5 \%$. Já o jardim de chuva gerou amortecimento médio no pico de vazão de $17,2 \%$.

De maneira similar ao ensaio anterior, a maior capacidade de amortecimento da vazão de pico observada no jardim de chuva se deve principalmente ao crivo instalado no extravasor do sistema de infiltração.

A Figura 7a apresenta as médias das porcentagens de água retida, infiltrada e extravasada em dois períodos de análise para o poço de infiltração, e a Figura $7 \mathrm{~b}$ apresenta esses resultados para o jardim de chuva, ambos para a vazão de $8,5 \mathrm{~m}^{3} / \mathrm{h}$. De maneira similar aos dados constantes na Figura 5, no período $\mathrm{T} 1$ tem-se a medição dos volumes percentuais imediatamente anteriores à ocorrência de extravasamento, e no período T2, os volumes percentuais imediatamente após o final do escoamento no extravasor.

No período T1, aproximadamente um terço do volume de água descarregada dentro do poço foi infiltrado nos $12 \mathrm{~min}$ iniciais. No período T2, igual a $20 \mathrm{~min}$ e $11 \mathrm{~s}$ contabilizados após o início da chuva simulada, $77,6 \%$ do volume gerado até aquele momento foi retido e infiltrado pelo sistema.

Por sua vez, em média 3,8\% da água descarregada dentro do jardim havia sido infiltrada até o início do extravasamento. No intervalo T2, que corresponde a 21 min e $30 \mathrm{~s}$ após o início da chuva simulada, em média $65,9 \%$ do volume gerado é retido e infiltrado pelo sistema.

Figura 5 - Volumes percentuais de infiltração, retenção e extravasamento para o ensaio com vazão de $6,8 \mathrm{~m}^{3} / \mathrm{h}$ e duração de $18 \mathrm{~min}$

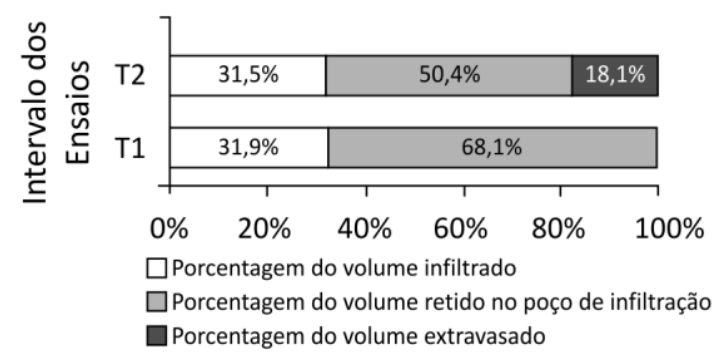

(a)

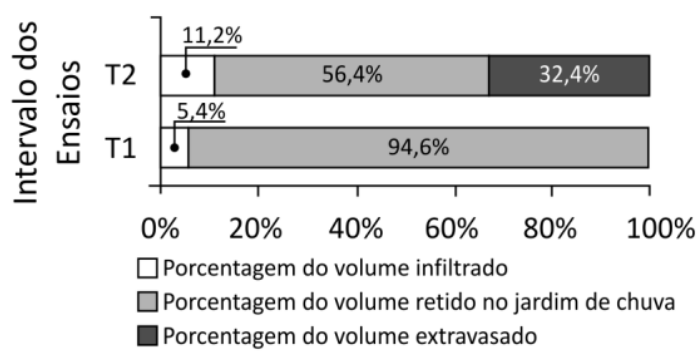

(b)

Nota: (a) Percentuais observados no poço de infiltração e (b) Percentuais monitorados no jardim de chuva.

Legenda: T1: Avaliação dos volumes percentuais imediatamente anterior ao início do extravasamento.

T2: Avaliação dos volumes percentuais imediatamente após o término do escoamento no tubo extravasor.

86 Reis, R. P. A.; Ilha, M. S. de O. 
Figura 6 - Hidrogramas de saída do sistema predial de água pluvial considerando cenários com e sem sistema de infiltração

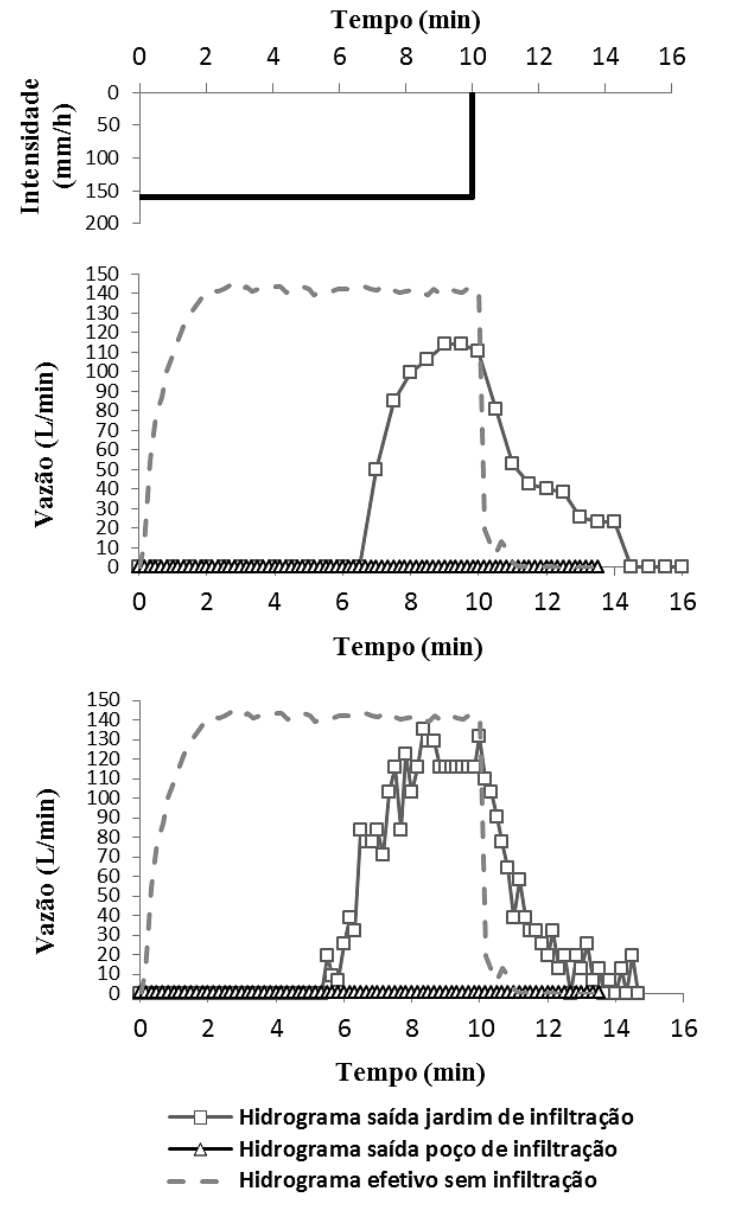

(a)
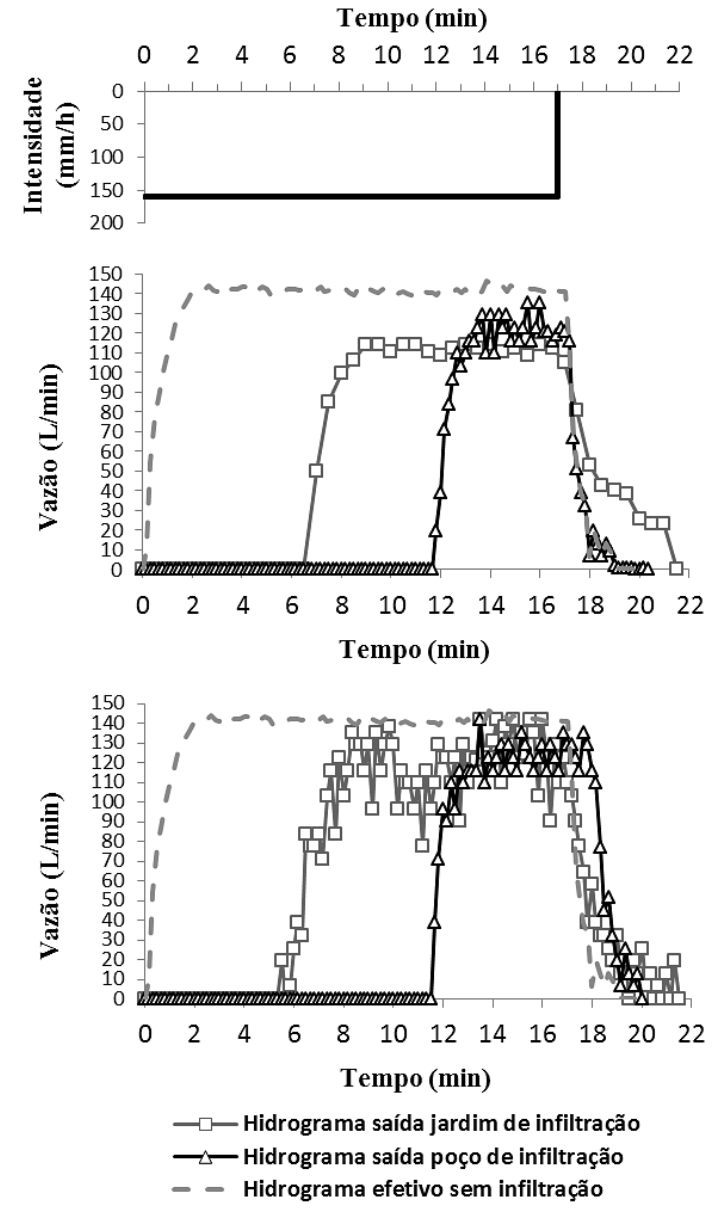

(b)

Nota: (a) Chuvas com período de retorno de 10 anos, vazão de $8,5 \mathrm{~m}^{3} / \mathrm{h}$ e duração de 10 min e (b) Prolongamento da vazão de $8,5 \mathrm{~m}^{3} / \mathrm{h}$ por um período de $17 \mathrm{~min}$, a fim de avaliar as condições de extravasamento.

Figura 7 - Volumes percentuais de infiltração, retenção e extravasamento para o ensaio com vazão de $8,5 \mathrm{~m}^{3} / \mathrm{h}$ e duração de $17 \mathrm{~min}$

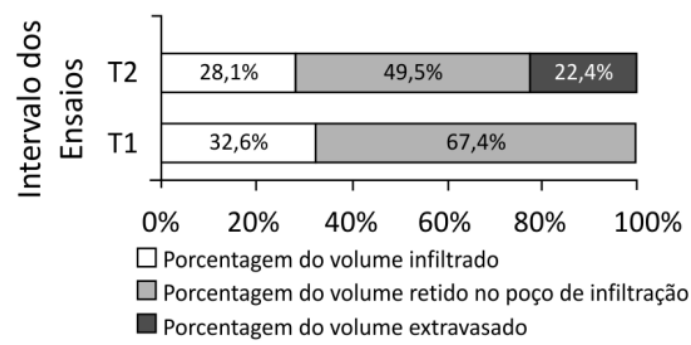

(a)

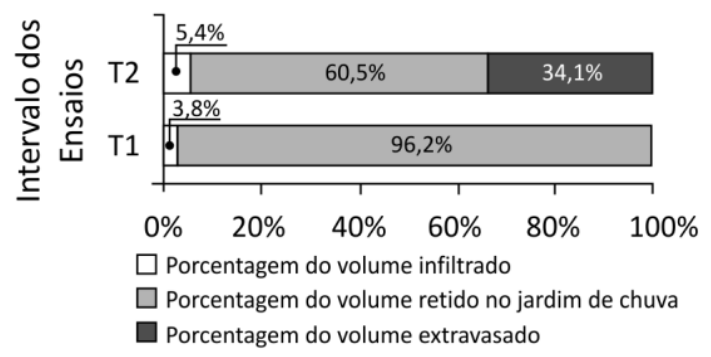

(b)

Nota: (a) Percentuais observados no poço de infiltração e (b) Percentuais monitorados no jardim de chuva.

Legenda: T1: Avaliação dos volumes percentuais imediatamente anterior o início do extravasamento.

T2: Avaliação dos volumes percentuais imediatamente após o término do escoamento no ubo extravasor. 
Novamente, no caso do poço de infiltração, uma parcela considerável do volume infiltrou durante o enchimento do sistema. Esse resultado ressalta que a parcela do volume infiltrado é um valor importante a ser considerado no dimensionamento do sistema de infiltração, mesmo para um solo de baixa taxa de permeabilidade e uma chuva de projeto de curta duração. Já para o jardim de chuva, a parcela de infiltração se mostrou pouco relevante para o dimensionamento, já que apenas $3,8 \%$ a $5,4 \%$ do volume infiltrou durante os ensaios.

Por fim, analisando-se os cenários de simulação das duas chuvas de projeto (3 e 10 anos), pode-se dizer que o poço de infiltração avaliado neste experimento obteve melhor desempenho para o controle do volume total de escoamento do que o jardim de chuva. Por sua vez, uma maior capacidade de amortecimento da vazão de pico foi observada no jardim de chuva, fenômeno atribuído ao crivo instalado no extravasor. Assim, se o sistema fosse dimensionado com uma capacidade maior, provavelmente teria um desempenho de retenção superior ao do poço de infiltração.

\section{Conclusões}

Os sistemas de infiltração de água de chuva são soluções com grande potencial para a compensação do aumento do escoamento da água pluvial gerado pela impermeabilização de áreas durante a construção de edificações. Por outro lado, um grande número de incertezas por parte do meio técnico a respeito do funcionamento e do desempenho dos sistemas de infiltração de água de chuva integrados aos sistemas prediais, em muitos casos, impede que as práticas de desenvolvimento de baixo impacto sejam abordadas com maior abrangência.

O desenvolvimento desta pesquisa, embasada na observação do funcionamento em campo de um jardim de chuva e de um poço de infiltração, pode auxiliar no estabelecimento de critérios mais precisos, que poderão ser utilizados para uma melhor concepção e implementação desses sistemas em áreas edificadas mais sustentáveis. Obviamente que estudos mais criteriosos de avaliação da capacidade estrutural do solo, de contaminação da água subterrânea, de permeabilidade do solo, de processos de manutenção, entre outros, devem ser considerados caso a caso, quando se pretende adotar sistemas de infiltração como práticas de baixo impacto na construção de edificações.

Este estudo mostrou que sistemas de infiltração de água de chuva podem ser integrados aos sistemas prediais de água pluvial, proporcionando redução do volume escoado e, também, amortecimento das vazões de pico do hidrograma de escoamento.

Os resultados obtidos mostraram que o poço de infiltração foi capaz de reter e infiltrar $100 \%$ de toda a vazão de projeto considerada no dimensionamento. Vale destacar, contudo, que o poço dimensionado, considerando-se o equacionamento usualmente empregado, resultou em um volume superestimado para as vazões ensaiadas. Mesmo quando submetido a condições extremas de operação, em que o volume de chuva foi maior que o suportado pelo poço de infiltração, ainda assim houve redução no pico de vazão de saída do sistema predial de água pluvial de entre $13 \%$ e $16 \%$.

Por sua vez, o dimensionamento do jardim de chuva gerou resultados muito próximos dos observados nos ensaios realizados, apesar de um pouco subestimados (aproximadamente 14\%). Por outro lado, quando este sistema foi submetido a condições de operação em que o volume de chuva foi maior que o por ele suportado, houve amortecimento no pico de vazão de saída do sistema predial de água pluvial de $17,2 \%$ a $22 \%$, valores superiores aos observados no poço de infiltração. Isso indica que, se o sistema fosse dimensionado com uma capacidade maior em termos de volume, equivalente ao superdimensionamento observado no poço de infiltração, provavelmente teria um desempenho de retenção superior ao do poço.

Os resultados obtidos indicam a necessidade de um amadurecimento nos processos de dimensionamento dos sistemas prediais de infiltração de água de chuva, já que o comportamento esperado, a partir do dimensionamento usual dos sistemas, o qual leva em conta apenas o volume de chuva gerado pela precipitação de projeto, não resultou desempenhos similares aos dos sistemas de infiltração investigados.

Em ambos os casos, os hidrogramas indicaram que a estrutura dos sistemas de infiltração proporcionou melhora no desempenho do sistema predial de água pluvial, conferindo, assim, maior grau de sustentabilidade com a gestão da água pluvial no próprio lote.

\section{Referências}

AGÊNCIA NACIONAL DE ÁGUA. Ministério do Meio Ambiente. Disponibilidade e Demandas de Recursos Hídricos no Brasil. Cadernos de Recursos Hídricos 2. Maio 2007. 
ASSOCIAÇÃO BRASILEIRA DE GEOLOGIA DE ENGENHARIA. Ensaios de Permeabilidade em Solos: orientações para sua execução no campo: procedimentos. São Paulo: ABGE, 1996. Boletim n. 4.

CAMPISANO, A.; CREACO, E.; MODICA, C. A Simplified approach For the Design of Infiltration Trenches. Water Science \& Technology, v. 64, n. 6, p. 1362-1367, 2011.

CARVALHO, E. T. L. Avaliação de Elementos de Infiltração de Águas Pluviais na Zona Norte da Cidade de Goiânia. Goiânia, 2008. 233 f. Dissertação (Mestrado em Engenharia Civil) Universidade Federal de Goiás, Goiânia, 2008.

CASAGRANDE, A. Classification and Identification of Soils. Transactions, v. 113, n. 2351, p. 901-903, 1948.

DAVIS, A. P. et al. Hydrologic Performance of Bioretention Storm-Water Control Measures. Journal of Hydrologic Engineering, v. 17, n. 5, p. 604-614, p. 2012

FEDERAL HIGHWAY ADMINISTRATION. Urban Drainage Design Manual. $2^{\text {nd }}$ ed. Washington: Departament of Transportation, 2001. Hydraulic Engineering Circular n. 22.

INSTITUTO BRASILEIRO DE GEOGRAFIA E ESTATÍSTICA. Sinópse do Censo Demográfico 2010: população residente, total, urbana total e urbana na sede municipal, em numerous absolutos e relativos, com indicação da area total e densidade demográfica, segundo as unidades da federação e os municípios. 2010. Disponível em: <http://www.censo2010.ibge.gov.br/sinopse/index. php?uf=35\&dados=0> Acesso em: 13 jun. 2014.

JACOBSON, D. Burnsville Rainwater Garden Retrofit Project. In: NONPOINT SOURCE POLLUTION CONFERENCE, 18., Burnsville, 2007. Proceedings... Burnsville, 2007.

JAMES, M. B.; DYMOND, R. L. Bioretention Hydrologic Performance in an Urban Stormwater Network. Journal of Hydrologic Engineering, v. 17, p. 431-436, 2012.

LIMA, V. C. G. da R. Análise Experimental e Numérica de Trincheiras de Infiltração em Meio Não Saturado. São Paulo, 2009. 170 f. Dissertação (Mestrado em Engenharia Civil) Escola de Engenharia de São Carlos, Universidade de São Paulo, São Paulo, 2009.
REIS, R. P. A. et al. Indicators of Water Supply and Drainage Systems im Brazilian Low Income Dwellings Considering Environmental Sustainability In: INTERNATIONAL SYMPOSIUM CIB W062 - WATER SUPPLY DRAINAGE FOR BUILDINGS, 32., Taipei, Taiwan. 2006. Proceedings... Taipei, Taiwan, 2006. v. 1.

REIS, R. P. A.; OLIVEIRA, L. H.; SALES, M. M. Sistemas de Drenagem na Fonte Por Poços de Infiltração de Águas Pluviais. Ambiente Construído, Porto Alegre, v. 8, n. 2, p. 88-117, abr./jun. 2008.

ROLDIN, M. et al. Modelling the Impact of Soakaway Retrofits on Combined Sewage Overflows in a $3 \mathrm{~km}^{2}$ Urban Catchment in Copenhagen, Denmark. Journal of Hydrology, p. 64-75, 2012.

SCHILLING, W. Cisterns Against Storms. In: FEATHERSTONE, R. E.; JAMES, A. Urban Systems Drainage. London: Computational Mechanics Centre, 1982. p. 7.49-4.60.

SOUZA, V. C. B.; GOLDENFUM, J. A.; BARRAUD, S. An Experimental and Numerical Study of Infiltration Trenches in Urban Runoff Control. In: INTERNATIONAL CONFERENCE ON URBAN DRAINAGE, 9., Portland, 2002. Proceedings... Portland, 2002.

ZUFFO, A. C.; LEME, P. E. GRADEX e Santa Barbara: método híbrido para cálculo de vazão de projeto para macrodrenagem urbana. In: SIMPÓSIO BRASILEIRO DE RECURSOS HÍDRICOS, 16., João Pessoa, 2005. Anais... João Pessoa, 2005.

WORLD ECONOMIC FORUM. Water Initiative Future Water Needs. Genova, Switzerland, 2009. $68 \mathrm{p}$.

XIAO, Q. et al. Hydrologic Processes at the Urban Residential Scale: hydrological process. Wiley InterScience, v. 21, p. 2174-2188, 2007.

\section{Agradecimentos}

À Capes, Fapesp, CNPq, Eternit, Aqualimp e Amanco. 


\section{Ricardo Prado Abreu Reis}

Escola de Engenharia Civil | Universidade Federal de Goiás | Praça Universitária, s/n, Bloco A, Sala 5, Setor Universitário | Goiânia - GO -

Brasil | CEP 74605-220 | Tel.: (62) 3209-6084 Ramal 205 | E-mail: ricardoprado.reis@outlook.com

Marina Sangoi de Oliveira llha

Departamento de Construção Civil, Faculdade de Engenharia Civil, Arquitetura e Urbanismo | Universidade Estadual de Campinas | Rua Albert Einsten, 951, Cidade Universitária | Campinas - SP - Brasil | Caixa Postal 6021 | CEP 13083-852 | Tel.: (19) 3521-2387 | E-mail: milha@fec.unicamp.br

Revista Ambiente Construído

Associação Nacional de Tecnologia do Ambiente Construído

Av. Osvaldo Aranha, $99-3^{\circ}$ andar, Centro

Porto Alegre - RS - Brasil

CEP 90035-190

Telefone: +55 (51) 3308-4084

Fax: +55 (51) 3308-4054

www.seer.ufrgs.br/ambienteconstruido

E-mail: ambienteconstruido@ufrgs.br

90 Reis, R. P. A.; Ilha, M. S. de O. 